\title{
A crack propagation-based life prediction model for lithium-ion batteries with Ni-rich layered cathodes
}

\section{Sun Ho Park}

Daegu Gyeongbuk Institute of Science and Technology

Joonam Park

Hanbat National University

\section{Youngjun Roh}

Daegu Gyeongbuk Institute of Science and Technology

\section{Seoungwoo Byun}

Daegu Gyeongbuk Institute of Science and Technology https://orcid.org/0000-0002-8951-2373

Hyobin Lee

Daegu Gyeongbuk Institute of Science and Technology

\section{Seungwon Jung}

Daegu Gyeongbuk Institute of Science and Technology

Nayeon Kim

Daegu Gyeongbuk Institute of Science and Technology

Yong Min Lee ( $\nabla$ yongmin.lee@dgist.ac.kr)

Daegu Gyeongbuk Institute of Science and Technology https://orcid.org/0000-0003-2002-2218

\section{Article}

Keywords: solid electrolyte interphase (SEI), lithium-ion batteries (LiBs), batteries, cathodes

Posted Date: June 24th, 2021

DOI: https://doi.org/10.21203/rs.3.rs-608604/v1

License: (c) (1) This work is licensed under a Creative Commons Attribution 4.0 International License.

Read Full License 


\section{Abstract}

The formation and growth of solid electrolyte interphase (SEI) are key parameters governing battery life prediction models of lithium-ion batteries (LiBs). However, as conventional battery life prediction models do not reflect other degradation parameters such as crack formation and propagation in high-nickel cathode materials, their accuracy is greatly reduced as the nickel content increases in layered oxide cathodes. Herein, we propose an advanced prediction model that includes both crack propagation and SEl growth. The reliability of this model was verified using experimental data of over 50 commercial $18650 \mathrm{LiB}$ cells, which were tested under depths of discharge and current rates, from 500 to 5,000 cycles. The proposed model can predict capacity retention values with less than $5 \%$ error, even in real operations at energy storage systems and electric vehicles. This model can provide a standard solution for predicting the cycle life of LiBs with high-nickel layered cathodes.

\section{Introduction}

Lithium-ion batteries (LiBs) are widely used in small devices and for large applications owing to their high energy density, high round-trip efficiency, and long cycle life. Moreover, as battery materials and designs are continuously developed, the battery operating conditions of the current rate and voltage range also increase, resulting in high capacity and power. ${ }^{1-3}$ However, LiB operation under harsh conditions can cause unexpected performance fade ${ }^{4-6}$ which makes it difficult to predict the remaining useful life (RUL) of batteries. This issue complicates the reliable operation and timely maintenance of LiBs in real applications. ${ }^{7}$ That is why the life prediction models for LiBs have been extensively studied and continuously modified. Specifically, when a battery cell or pack is selected, and the operating conditions such as the discharge/charge power, usable depth-of-discharge (DOD) range, and temperature limit are set, a battery life prediction model can mathematically provide us with desirable operating conditions or a reasonable warranty period. Furthermore, the construction of multi-physical models based on electrochemistry would enable the design parameters of battery cells, modules, or packs to be explored in advance.

Although an electrochemical model that reflects all LiB degradation mechanisms is very attractive, it is challenging to strike an appropriate balance between model complexity and prediction accuracy. ${ }^{8}$ Various battery life prediction models for LiBs have been reported, but most models predict the RUL by simulating a few mechanisms related to the solid electrolyte interphase (SEI). ${ }^{9-16} \mathrm{Fig}$. S1 presents a comprehensive overview of battery life prediction models based on the mechanism of SEl formation and growth on the anode in LiBs. For example, Ramadass et al. suggested a semi-empirical battery life prediction model by connecting the increase in resistance caused by the SEl with the number of cycles in the form of an Arrhenius equation. ${ }^{9}$ Moreover, Ploehn et al. first provided a physics-based battery life prediction model by creating stoichiometric equations and connecting them to the limitation of solvent diffusion. ${ }^{10}$ Subsequently, Christensen et al. took a more physical approach by incorporating the kinetic limitation. ${ }^{11}$ In the 2010s, structural factors such as the porosity effect and cracks in the SEl caused by volume 
expansion of the anode active material were incorporated to more realistically simulate SEI growth. ${ }^{12-15}$ Park et al. considered the electrolyte depletion stoichiometrically connecting to the formation of SEl layer on the anode. ${ }^{17}$ Herein, what we should be aware of in previous works concerned with the SEI model is that most of them chose the cathode active materials which have good structural and thermal stability $\left(\mathrm{LiFePO}_{4}\right.$ or $\left.\mathrm{LiCoO}_{2}\right)$, and the cells were operated under mild operating conditions. In other words, the performance of existing SEl models is not sufficient to predict current $\mathrm{LiBs}$, including high-nickel active materials such as $\mathrm{LiNi}_{x} \mathrm{Co}_{y} \mathrm{Al}_{z} \mathrm{O}_{2}(\mathrm{NCA}, \mathrm{x} \geq 0.8, x+y+z=1)$ or $\mathrm{LiNi}_{x} \mathrm{Co}_{y} \mathrm{Mn}_{z} \mathrm{O}_{2}(\mathrm{NCM}, \mathrm{x} \geq 0.6, x+y+z=1)$. Cases where $\mathrm{LiBs}$ are operated under severe conditions represent an even more difficult problem. ${ }^{18}$

The use of high-nickel cathode materials is crucial for securing LiB systems with high energy density and a competitive price, despite the fact that the structure of particles containing abundant nickel induces additional degradation. ${ }^{4,19}$ Thus, it is important to combine degradation of the SEl layer at the anode with other degradation phenomena, that is, high-nickel active materials, in order to accurately predict the lifetime of LiBs currently released on the market. Although there are various fundamental degradation mechanisms that occur at the high-nickel cathode, particle cracking is the final outcome affecting poor cycle performance. ${ }^{20}$ The cracks in cathode active materials lead to additional electrolyte decomposition, which increases the resistance of the cell and decreases the conductivity because of newly created gaps between broken particles. ${ }^{21,22}$ Some research groups have modeled the degradation of high-Ni cathode active materials, ${ }^{23-26}$ which we distinguish into two approaches: atomic and microscopic, as depicted in Fig. S2. As an example of the atomic approach, Yang et al. demonstrated the defect-induced phase transition through a first-principles calculation study. ${ }^{23}$ Das et al. proposed a model reflecting rock-salt structures, as well as the kinetics of the phase transformation. ${ }^{24}$ As for microscopic approaches, Zhang et al. modeled the cracking process of a secondary particle according to the fracture energies, ${ }^{25}$ whereas Moon et al. compared the amount of cathode active material forced between pristine and Mg-doped surfaces. ${ }^{26}$ Although these studies analyzed how the crack growth in the cathode active material affects capacity degradation, they did not determine the relationship between crack growth and LiB capacity loss nor expand this point to the battery life prediction model.

In this study, we first propose a highly applicable battery life prediction model that couples the degradation equations of cathode cracks and anode SEls with an electrochemical model based on a pseudo-2-dimensional (P2D) model. To verify the results simulated by our model, we compare them with experimental data for more than 50 NCA 18650 cylindrical cells over 500 to 5,000 cycles at different DOD and current rate (C-rate) conditions (see Experimental Methods in Supporting Information). Furthermore, a few cells are operated under the actual conditions of energy storage systems (ESSs) and electric vehicles (EVs) to validate the reliability of the proposed model, which attains a prediction error of less than $5 \%$ in all tests.

\section{Results And Discussion}


Assuming that an air conditioning device would maintain the battery surroundings at room temperature $\left(25^{\circ} \mathrm{C}\right)$, C-rates of $0.5,1$, and $2 \mathrm{C}$ and DOD values of 10,50 , and $100 \%$ were set. These operating conditions were derived by investigating the real conditions of ESSs and EVs. Cycle performance tests were conducted until an accumulated capacity of 2,700 Ah, equal to 500 cycles of a $2.7 \mathrm{Ah} \mathrm{LiB}$, when using its full voltage range of 2.5-4.2. The accumulated capacity allows accurate comparisons in situations where the same capacity is applied to batteries operated under different conditions. Figure 1a shows the cycle life results of DOD 10,50, and 100\% under $0.5 \mathrm{C}$ charge and discharge, which indicate greater capacity loss with a wider DOD range. Notably, the capacity loss due to a high C-rate over a narrow DOD range was not high, whereas a high C-rate effect was observed over a broad DOD range (Fig. 1b and c). The cross-sectional images taken from initial and cycled cells using ion milling equipment (Hitachi, IM4000), revealed cracking of NCA particles during operation. In the wider range of DOD conditions, more extensively cracked NCA primary particles were observed (Fig. 1a, $\bigotimes-\bigotimes)$. Moreover, substantial degradation was observed at a high C-rate over a broad DOD range, e.g., 100\%, whereas only minor degradation occurred over a narrow DOD range (Fig. 1b and c, $\rrbracket-\rrbracket)$. These results imply that the cracking of high-nickel active materials predominantly ascribes a used number of sites where lithium-ion can be located in active material rather than intercalated or de-intercalated frequency of lithium-ions at specific sites.

To reflect the cracking degradation of particles under specific conditions in our modeling process, crosssectional images of cycled active materials were analyzed using ImageJ software, which is an image processing program. Each cross-sectional SEM image was first treated by the threshold method to extract the desired particle by adjusting the digitized image containing under- or over-exposed pixels. The edge finding and outline process were followed by perimeter calculation. The computer-modified images provided quantified values of crack area size. Figure 2 shows a 3D graph of the perimeter change at DODs of 10,50 , and 100 and C-rates of $0.5 \mathrm{C}, 1 \mathrm{C}$, and $2 \mathrm{C}$. The normalized perimeter change was calculated as the change in the value compared to the previous value. That is, the normalized perimeter change is an index of the cracking impact under different operating conditions. In the case of this active material, the normalized perimeter change depended more strongly on the DOD than the C-rate. Based on the above investigation of the experimental results, the crack degradation equation for the high-nickel active material was constructed as an applied form of the Arrhenius equation (Eq. 1), where " $t_{c}$ " is a degradation factor adopting a power law relationship with time $(\mathrm{t}), \mathrm{C}_{\text {rate }}$ is the $\mathrm{C}$-rate, $\mathrm{N}$. Peri. Change is the normalized cracked-perimeter of the particle, and $k_{1}, k_{2}$, and $k_{3}$ are three fitting parameters.

$$
t_{c}=t^{k_{1}} \cdot \exp \left(\frac{-U_{0}+k_{2} * C_{\text {rate }}}{R T}\right) *\left(\sum N . \text { Peri. Change }\right)^{k_{3}}
$$

As the cycle was repeated, the amount of degradation was summed and represented as a factor affecting the electrical conductivity and resistance film of the active material. ${ }^{21,22}$ Each value was formed using a linear composite function, as indicated in Eqs. 2 and 3. os.crack is the effective conductivity of the cathode 
particle and $R_{\text {film.p }}$ is the effective resistance film of the cathode, which is affected by $t_{c}$ and correlated by two fitting parameters $\left(k_{4}\right.$ and $\left.k_{5}\right)$.

$$
\begin{gathered}
\sigma_{s, \text { crack }}=\sigma_{s, 0} *\left(1+k_{4} t_{c}\right) \\
R_{\text {film }, p}=R_{f i l m, p 0} *\left(1+k_{5} t_{c}\right)
\end{gathered}
$$

To confirm the performance of our model, we compared its simulated capacity retention to the experimental data and simulation results of two representative SEI models: an SEI model and a thermal SEl model. ${ }^{14,27}$ Fig. 3a displays the evaluated boundary conditions of the DOD and C-rate. Herein, four vertex conditions were selected and compared; if these results were highly correlated with the experimental results, the other conditions inside the quadrangle were highly likely to be closely correlated. Consequently, the pre-reported SEI models and our developed model showed high prediction capability under the conditions of DOD 10 and $0.5 \mathrm{C}$ (Fig. 3b). At a broader DOD range or higher C-rate, our model guaranteed an average error of less than $5 \%$, whereas the prediction rate of previous models was very low (Fig. 3c-e). The above results indicate that the newly proposed model considering crack degradation is highly practical for the battery life prediction of high-nickel cathode-based cells. In addition, three models were simulated under arbitrary conditions (DOD 50 and 1C) to confirm the validity of our model, which confirmed its higher prediction rate compared to previous models (Fig. 3f).

The performance of our developed model was verified by simulations of the cells into real systems, i.e., ESSs and EVs. ESSs can overcome the time difference in their production and consumption or increase the power quality, which is typically achieved by three operating scenarios: peak shaving (PS), renewable integration (RI), and frequency regulation (FR). ${ }^{28,29}$ PS was characterized by operation at a low rate of approximately $0.5 \mathrm{C}$ (Fig. S3a) or less in all battery voltage ranges (3.0-4.4 V) (Fig. 4a) where the simulation results were combined. The average error range of the voltage profile and the surface temperature was within $1.15 \%$ and $0.6{ }^{\circ} \mathrm{C}$, respectively. Rl, which stabilizes the intermittent power generated by the sun or wind, operated at a very low rate of $0.2 \mathrm{C}$ or less (Fig. S3b), and the voltage was swept at $3.74 \mathrm{~V}$ (Fig. 4b). As a result, the voltage error between the simulation and experiment was approximately $0.75 \%$. Finally, FR increased substantially with a high rate of approximately $2 \mathrm{C}$ and operated over the entire voltage range with frequent current direction changes within a short time (Fig. S3c and Fig. 4c). Our model simulated similar results to the experiments at all operating durations, with no significant differences in voltage or temperature.

In addition to the operating patterns for ESSs, two representative EV scenarios were simulated by our model: the urban dynamometer driving schedule (UDDS) and the worldwide harmonized light vehicles test procedure (WLTP) ${ }^{30}$ The UDDS had a dominant level of $0.5 \mathrm{C}$ and intermittently applied a C-rate 
range of 1 and 1.5, whereas the WLTP included a high C-rate of $2 \mathrm{C}$ at the end of the pattern to mimic high car speeds (Fig. S4a, b). The simulated fluctuations of cell voltage and temperature under both scenarios were well matched with the experimental data (Fig. 4d, e). To verify the feasibility of our battery life prediction model, the error rates were compared between the simulated capacity retention of all results and the one-year accumulated data. All error rates were within $5 \%$ (Fig. 4f, g). These outcomes indicate that our battery life prediction model, which reflects the cracking of high-nickel active material and SEI formation, is a strong candidate for accurately predicting LiB cycle lives under various operating conditions.

\section{Conclusions}

In this study, we proposed an advanced battery life prediction model for LiBs that mimics two major types of degradation: cracking of cathode materials and SEl formation. This model is termed the crackpropagation-based battery life prediction model. The performance of our model was validated by comparative studies with two previous representative battery life prediction models and a large amount of experimental data. The greatest advantage of the newly developed model is its ability to predict not only very complex fluctuations of voltage and temperature under random current or power conditions but also the battery life over one year of operation with an error rate of only $5 \%$. The model performance was verified for five scenarios: peak shaving, renewable integration, frequency regulation, the urban dynamometer driving schedule, and the worldwide harmonized light vehicles test procedure. We believe that the proposed crack-propagation-based battery life prediction model makes a significant contribution to battery life prediction for commercial LiBs and represents a basic model for physics-based battery life prediction models.

\section{Methods}

Cell Tests. A total of 50 commercial NCA/graphite cylindrical cells (Samsung SDI, model INR 18650, 2.7 Ah nominal capacity) were used in this study. The cells were cycled in 32 channels in a PNE Solution cycler $(5.0 \mathrm{~V} / 10.00 \mathrm{~A}, 1.00 \mathrm{~A}, 0.10 \mathrm{~A})$ at various $\mathrm{C}$-rates $(0.5 \mathrm{C}, 1 \mathrm{C}$, and $2 \mathrm{C})$ and depth of discharge (DOD) conditions $(10,50$, and 100$)$. All cell tests were performed in a temperature-controlled chamber (JSR Cooled Incubator) at $25^{\circ} \mathrm{C}$.

When the cells reached the same 2,700 Ah accumulated capacity, they were disassembled using a saw blade (TOTAL) in a dry room (dew point $-40^{\circ} \mathrm{C}$ ). Each positive electrode was first treated with dimethyl carbonate (DMC) solvent to remove the lithium salt and placed in a vacuum chamber for over 8 hours. Ion milling (Hitachi-IM4000 4k eV 40 min) was followed by scanning electron microscopy (SEM, HitachiSU8020) to obtain a cross-sectional image of the cracking phenomenon.

Modeling: Thermal Coupled P2D, SEl Formation, and High-nickel Active Material Cracking. The governing equations and boundary conditions for thermal phenomena must be included for predicting the electrochemical performance of batteries in the energy storage system (ESS) and electric vehicle (EV). 
Therefore, we created an additional thermal model with another dimension (3D) and exchanged only necessary values toward a pseudo-2-dimensional (P2D) model (Fig. S5 shows a schematic of the developed model). The temperature change of the lithium-ion battery (LiB) was calculated based on the 3D thermal model and substituted into the P2D model; accordingly, the heat generation values calculated from the P2D model were returned to the 3D thermal model. The results were derived from these repetitive calculations.

In the electrochemical process, if a commercial LiB is not operated under severe working conditions (i.e., high voltage or high C-rate), the solid electrolyte interphase (SEI) layer degradation resulting from expansion and contraction of the negative electrode volume is the main cause of capacity loss. ${ }^{31}$ Ekstrom and Lindbergh derived an aging model based on the contribution of SEl formation/growth with four fitting parameters. ${ }^{14}$ Liang et al. then advanced this model by considering the thermal effect. ${ }^{27}$ This SEl and thermal SEI models are simulated under different operating conditions in order to demonstrate the advance of our new model and shown in Fig. 3 with the following notation: SEl model (15') and thermal SEl model $\left(20^{\prime}\right)$. In Ref. 14 , the term $\mathrm{i}_{\mathrm{SEI}}\left(\mathrm{A} / \mathrm{m}^{2}\right)$ represents the local current density for forming the SEl layer on the anode surface; this degradation equation consists of two types of degradation dependent variable, $\mathrm{K}_{\mathrm{crd}}$, which reflects the influence of SOC on anode expansion. The SEI degradation equation has four fitting parameters $(H, a, J$, and $f)$ where each fitting parameter has the advantage of expanding the development of LiBs' life prediction models. The calculated $\mathrm{i}_{\mathrm{SEI}}$ was substituted for the concentration of the $S E I$ layer $\left(C_{S E I}\right)$. The overvoltage $\left(\eta_{S E I}\right)$ formed by the SEl layer affects the next local current density in turn. $A_{v}$ is the specific surface area of the negative electrode surface, which can vary depending on the state of charge (SOC).

Even though some studies have developed life prediction models that consider growth and formation of the passive SEl layer, large errors existed between the simulations and experiments in specific sections. Therefore, we additionally included the crack degradation phenomenon of the cathode active material in the prior life prediction. The aim was to calculate the perimeter change of the cracked particle and connect it to the loss of electric conductivity and increased resistance of the electrode (see main text for details).

\section{Declarations}

\section{Acknowledgement}

This research was supported by the Basic Research Laboratory (NRF-2020R1A4A4079810), the Future Materials Discovery Program (NRF-2020M3D1A1110527), and Energy Cloud R\&D Program (2021M3H4A1A02048529) through National Research Foundation of Korea (NRF) grant funded by Ministry of Science and ICT.

\section{References}


1. Vehicle Technology Office, Advanced Battery Development, System Analysis, and Testing, https://www.energy.gov/eere/vehicles/advanced-battery-development-system-analysis-andtesting

2. Baldwin, S.; Williams, E.; Russomanno, C., Technology Transition Case Study. United Stated Advanced Battery consortium 2015.

3. Cao, D.; Zhao, Y.; Sun, X.; Natan, A.; Wang, Y.; Xiang, P.; Wang, W.; Zhu, H., Processing Strategies to Improve Cell-Level Energy Density of Metal Sulfide Electrolyte-Based All-Solid-State Li Metal Batteries and Beyond. ACS Energy Letters 2020, 5 (11), 3468-3489.

4. Liu, H.; Wolf, M.; Karki, K.; Yu, Y. S.; Stach, E. A.; Cabana, J.; Chapman, K. W.; Chupas, P. J., Intergranular Cracking as a Major Cause of Long-Term Capacity Fading of Layered Cathodes. Nano Letters 2017, 17 (6), 3452-3457.

5. Liu, L.; Park, J.; Lin, X.; Sastry, A. M.; Lu, W., A thermal-electrochemical model that gives spatialdependent growth of solid electrolyte interphase in a Li-ion battery. Journal of Power Sources 2014, 268, 482-490.

6. Deshpande, R.; Verbrugge, M.; Cheng, Y.-T.; Wang, J.; Liu, P., Battery Cycle Life Prediction with Coupled Chemical Degradation and Fatigue Mechanics. Journal of The Electrochemical Society 2012, 159 (10), A1730-A1738.

7. Hu, X.; Xu, L.; Lin, X.; Pecht, M., Battery Lifetime Prognostics. Joule 2020, 4 (2), 310-346.

8. $\quad$ Severson, K. A.; Attia, P. M.; Jin, N.; Perkins, N.; Jiang, B.; Yang, Z.; Chen, M. H.; Aykol, M.; Herring, P. K.; Fraggedakis, D.; Bazant, M. Z.; Harris, S. J.; Chueh, W. C.; Braatz, R. D., Data-driven prediction of battery cycle life before capacity degradation. Nature Energy 2019, 4 (5), 383-391.

9. Ramadass, P.; Haran, B.; White, R.; Popov, B. N., Mathematical modeling of the capacity fade of Li-ion cells. Journal of Power Sources 2003, 123 (2), 230-240.

10. Ploehn, H. J.; Ramadass, P.; White, R. E., Solvent Diffusion Model for Aging of Lithium-lon Battery Cells. Journal of The Electrochemical Society 2004, 151 (3).

11. Christensen, J.; Newman, J., Cyclable Lithium and Capacity Loss in Li-lon Cells. Journal of The Electrochemical Society 2005, 152 (4).

12. Safari, M.; Morcrette, M.; Teyssot, A.; Delacourt, C., Multimodal Physics-Based Aging Model for Life Prediction of Li-lon Batteries. Journal of The Electrochemical Society 2009, 156 (3).

13. Tang, M.; Lu, S.; Newman, J., Experimental and Theoretical Investigation of Solid-ElectrolyteInterphase Formation Mechanisms on Glassy Carbon. Journal of The Electrochemical Society 2012, 159 (11), A1775-A1785. 
14. Ekström, H.; Lindbergh, G., A Model for Predicting Capacity Fade due to SEl Formation in a Commercial Graphite/LiFePO ${ }_{4}$ Cell. Journal of The Electrochemical Society 2015, 162 (6), A1003-A1007.

15. Kupper, C.; Weißhar, B.; Rißmann, S.; Bessler, W. G., End-of-Life Prediction of a Lithium-lon Battery Cell Based on Mechanistic Aging Models of the Graphite Electrode. Journal of The Electrochemical Society 2018, 165 (14), A3468-A3480.

16. Reniers, J. M.; Mulder, G.; Howey, D. A., Review and Performance Comparison of MechanicalChemical Degradation Models for Lithium-Ion Batteries. Journal of The Electrochemical Society 2019, 166 (14), A3189-A3200.

17. Park, J.; Appiah, W. A.; Byun, S.; Jin, D.; Ryou, M.-H.; Lee, Y. M., Semi-empirical long-term cycle life model coupled with an electrolyte depletion function for large-format graphite/LiFePO ${ }_{4}$ lithium-ion batteries. Journal of Power Sources 2017, 365, 257-265.

18. Nam, G. W.; Park, N.-Y.; Park, K.-J.; Yang, J.; Liu, J.; Yoon, C. S.; Sun, Y.-K., Capacity Fading of NiRich NCA Cathodes: Effect of Microcracking Extent. ACS Energy Letters 2019, 4 (12), 2995-3001.

19. Hsieh, I. Y. L.; Pan, M. S.; Chiang, Y.-M.; Green, W. H., Learning only buys you so much: Practical limits on battery price reduction. Applied Energy 2019, 239, 218-224.

20. Park, K.-J.; Hwang, J.-Y.; Ryu, H.-H.; Maglia, F.; Kim, S.-J.; Lamp, P.; Yoon, C. S.; Sun, Y.-K., Degradation Mechanism of Ni-Enriched NCA Cathode for Lithium Batteries: Are Microcracks Really Critical? ACS Energy Letters 2019, 4 (6), 1394-1400.

21. Watanabe, S.; Kinoshita, M.; Hosokawa, T.; Morigaki, K.; Nakura, K., Capacity fade of $\mathrm{LiAl}_{y} \mathrm{Ni}_{1-x-y} \mathrm{Co}_{x} \mathrm{O}_{2}$ cathode for lithium-ion batteries during accelerated calendar and cycle life tests (surface analysis of $\mathrm{LiAl}_{y} \mathrm{Ni}_{1-x-y} \mathrm{Co}_{x} \mathrm{O}_{2}$ cathode after cycle tests in restricted depth of discharge ranges). Journal of Power Sources 2014, 258, 210-217.

22. Sallis, S.; Pereira, N.; Mukherjee, P.; Quackenbush, N. F.; Faenza, N.; Schlueter, C.; Lee, T. L.; Yang, W. L.; Cosandey, F.; Amatucci, G. G.; Piper, L. F. J., Surface degradation of $\mathrm{Li}_{1-\mathrm{x}} \mathrm{Ni}_{0.80} \mathrm{Co}_{0.15} \mathrm{Al}_{0.05} \mathrm{O}_{2}$ cathodes: Correlating charge transfer impedance with surface phase transformations. Applied Physics Letters 2016, 108 (26).

23. Yang, C.; Shao, R.; Wang, Q.; Zhou, T.; Lu, J.; Jiang, N.; Gao, P.; Liu, W.; Yu, Y.; Zhou, H., Bulk and surface degradation in layered Ni-rich cathode for $\mathrm{Li}$ ions batteries: Defect proliferation via chain reaction mechanism. Energy Storage Materials 2021, 35, 62-69.

24. Das, H.; Urban, A.; Huang, W.; Ceder, G., First-Principles Simulation of the (Li-Ni-Vacancy)O Phase Diagram and Its Relevance for the Surface Phases in Ni-Rich Li-lon Cathode Materials. Chemistry of Materials 2017, 29 (18), 7840-7851. 
25. Zhang, Y.; Zhao, C.; Guo, Z., Simulation of crack behavior of secondary particles in Li-ion battery electrodes during lithiation/de-lithiation cycles. International Journal of Mechanical Sciences 2019, 155, 178-186.

26. Moon, J.; Jung, J. Y.; Hoang, T. D.; Rhee, D. Y.; Lee, H. B.; Park, M.-S.; Yu, J.-S., The correlation between particle hardness and cycle performance of layered cathode materials for lithium-ion batteries. Journal of Power Sources 2021, 486.

27. Liang, J.; Gan, Y.; Yao, M.; Li, Y., Numerical analysis of capacity fading for a $\mathrm{LiFePO}_{4}$ battery under different current rates and ambient temperatures. International Journal of Heat and Mass Transfer 2021, 165.

28. LG Energy Solution., ESS Battery Division. https://www.Igessbattery.com/m/eu/grid/intro.Ig

29. Hwang, I.; Jung, Y., Korea's Energy Storage System Development: The Synergy of Public Pull and Private Push. World Bank Group Korea Office, Innovation and Technology Notes 2020.

30. Fotouhi, A.; Propp, K., Auger, D. J., Electric Vehicle Battery Model Identification and State of Charge Estimation in Real World Driving Cycles. Proceedings of the $7^{\text {th }}$ computer science and electronic engineering conference 2015.

31. Wang, A.; Kadam, S.; Li, H.; Shi, S.; Qi, Y., Review on modeling of the anode solid electrolyte interphase (SEI) for lithium-ion batteries. npj. Computational Materials 2018, 4:15

\section{Figures}

(a)
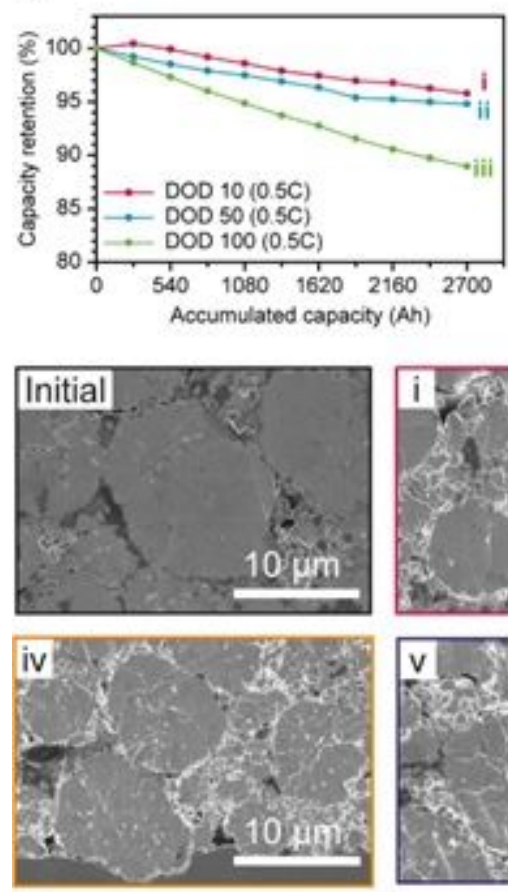

(b)

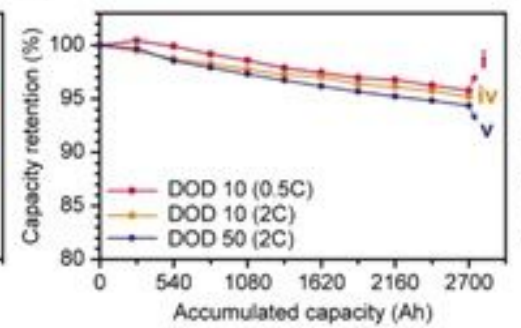

(c)

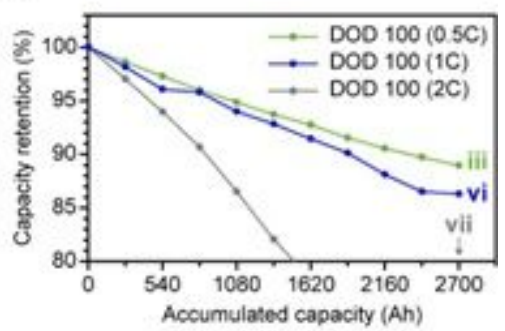

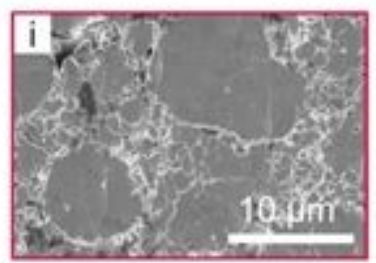

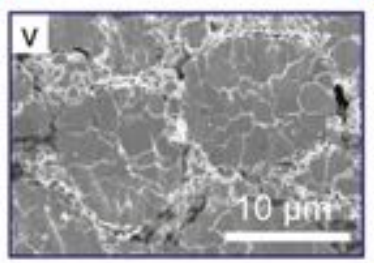

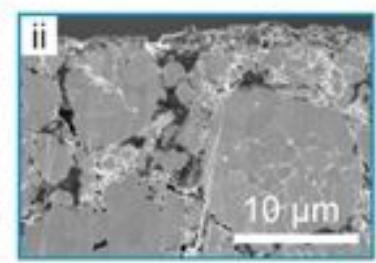

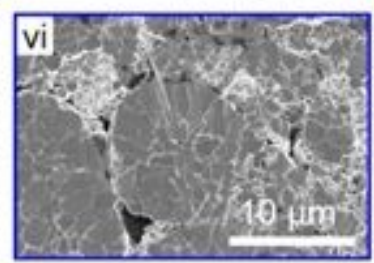

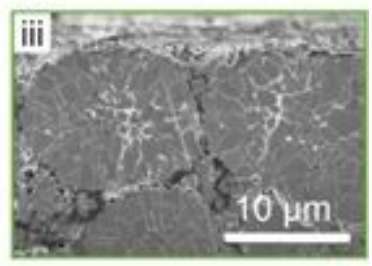

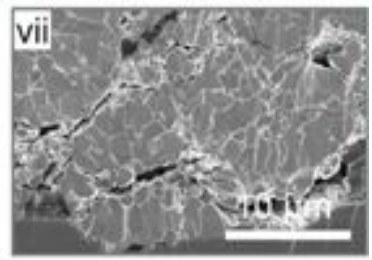


Figure 1

(a-c) Cycling performance evaluated at different C-rate (0.5C and 2C) and DOD (10, 50, and 100)

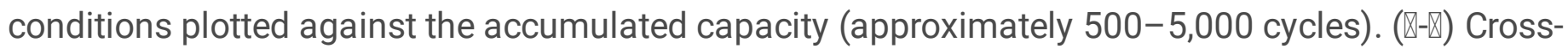
sectional SEM images of cathode active material captured after an accumulated capacity of 2,700 Ah.

DOD $10(0.5 C)$

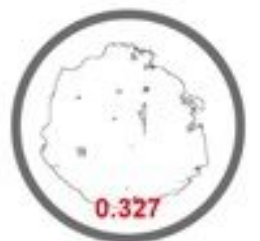

DOD $50(0.5 \mathrm{C})$

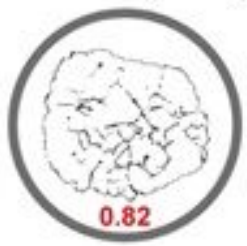

DOD $50(2 \mathrm{C})$
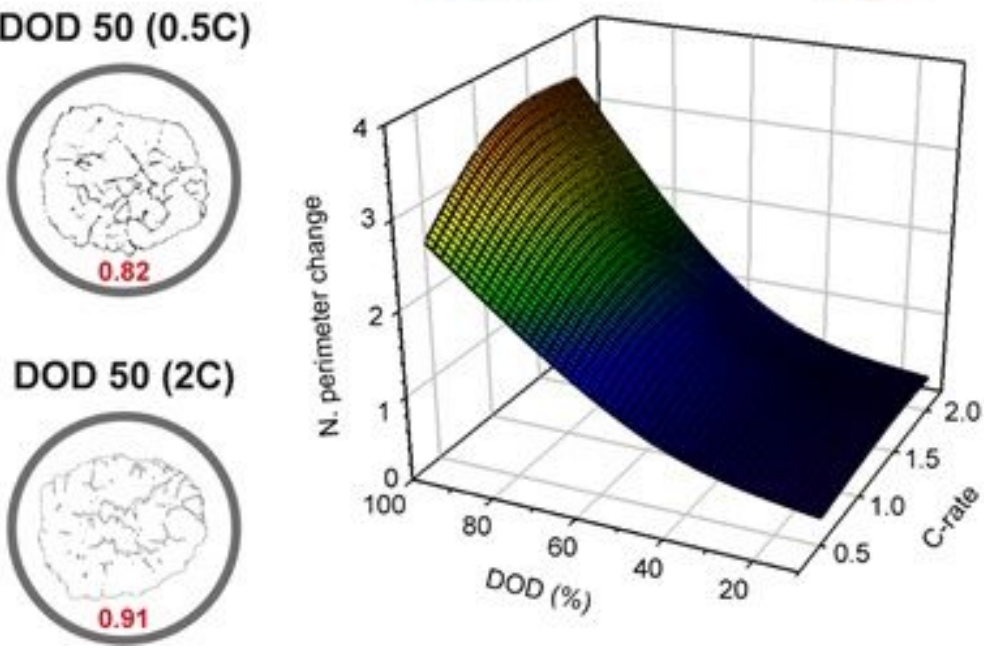

DOD $10(2 \mathrm{C})$

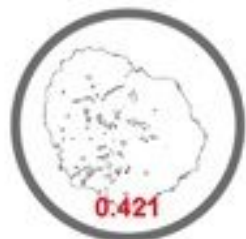

DOD $100(0.5 C)$

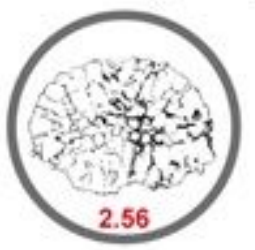

DOD $100(2 C)$

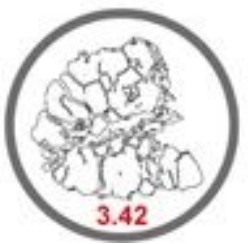

Figure 2

Processed images of cathode particles under different operating conditions (DOD 10, 50, and 100 and $0.5 \mathrm{C}, 1 \mathrm{C}$, and $2 \mathrm{C}$ ) with normalized perimeter change values (indicated in red color). And these values (denoted as N. perimeter change) are used in 3D graph against the DOD and C-rate. 
(a)

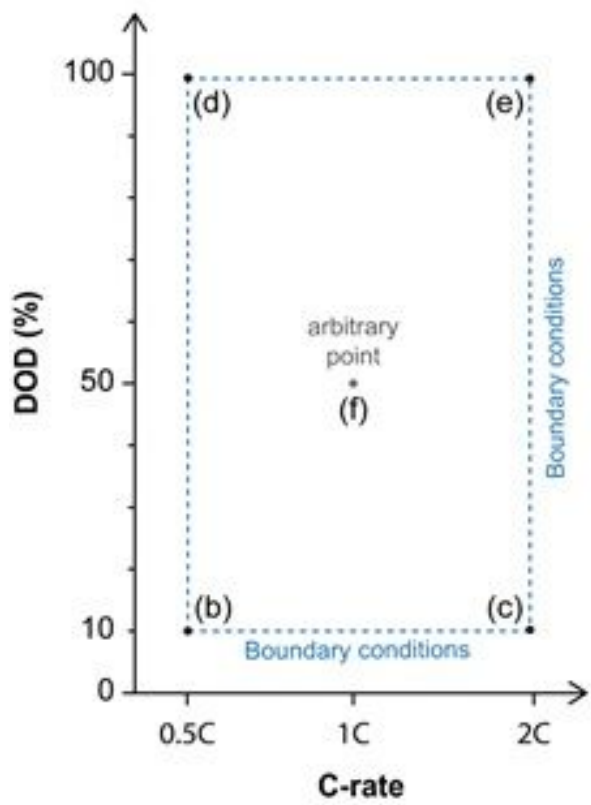

(f)

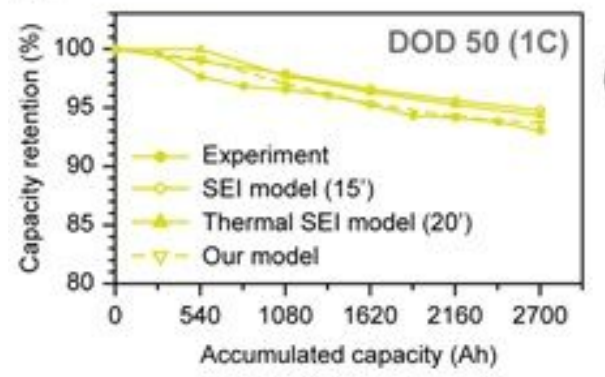

(b)

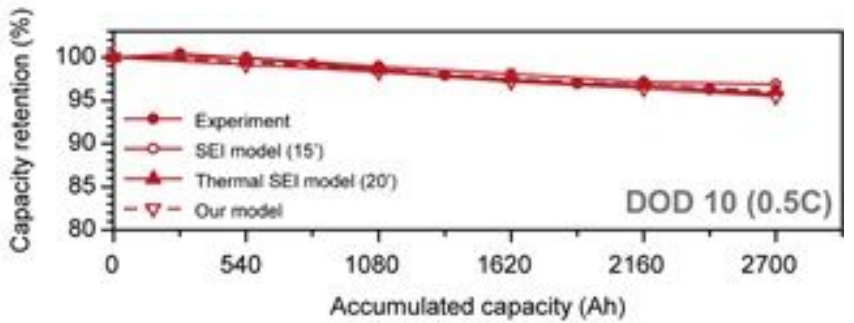

(c)

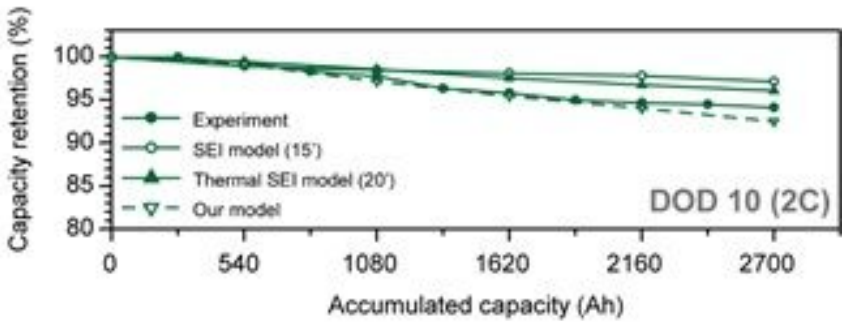

(d)

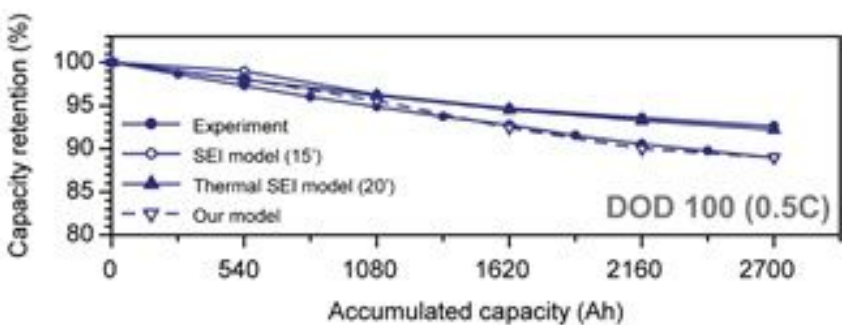

(e)

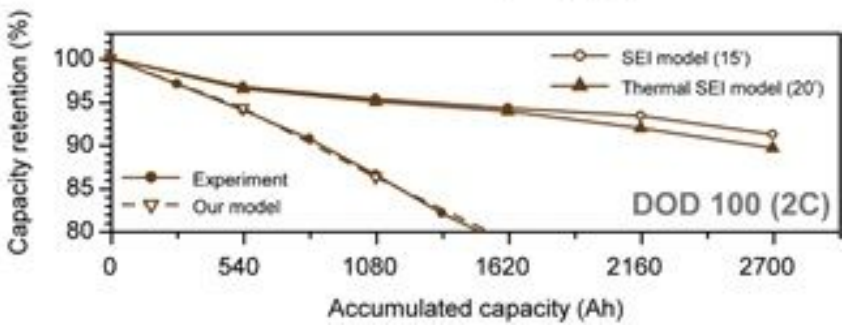

Figure 3

(a) C-rate and DOD boundary conditions, and arbitrary point. (b-e) Capacity retention tested at four-point boundary conditions; (b) DOD 10 (0.5C), (c) DOD 10 (2C), (d) DOD 100 (0.5C), (e) DOD 100 (2C), and (f) arbitrary point (DOD50, 1C). 
(a)

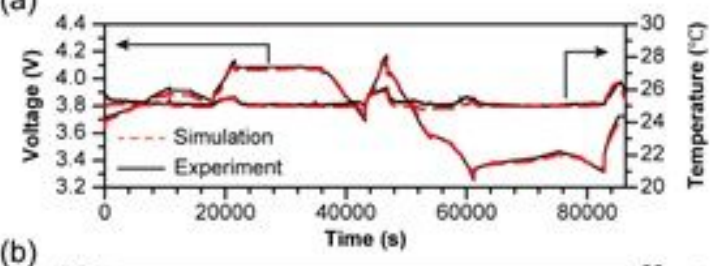

(b)

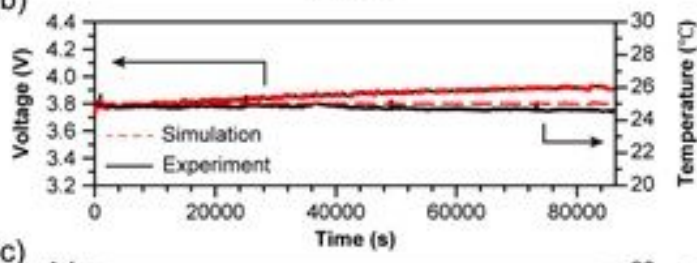

(c)
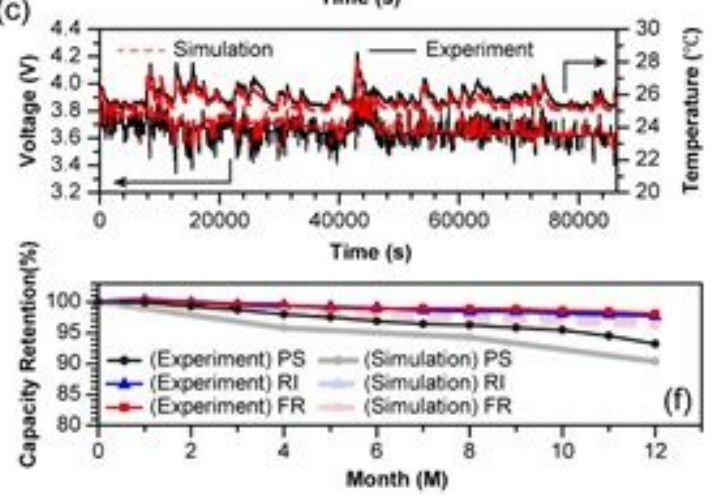

(d)

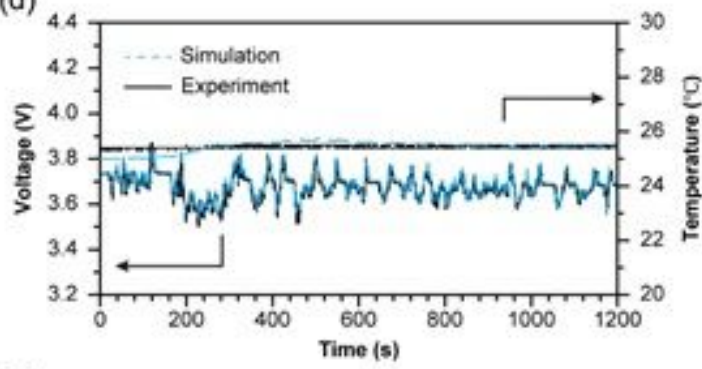

(e)
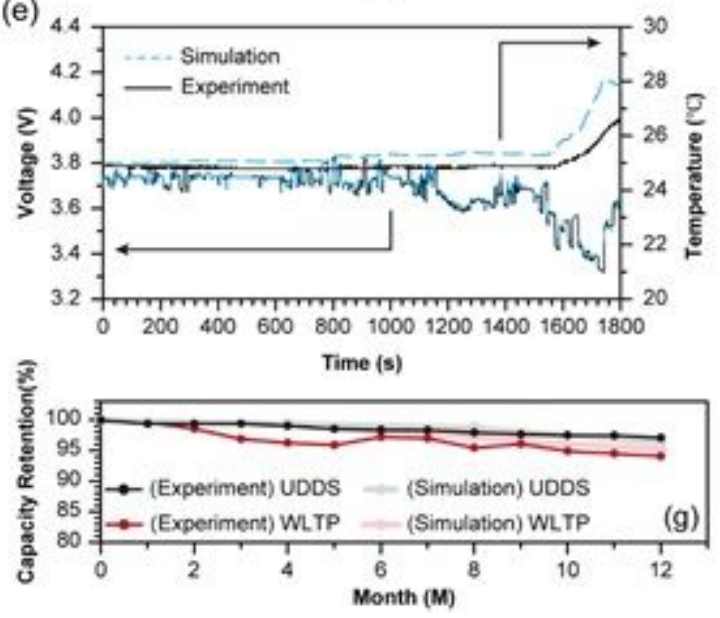

\section{Figure 4}

Time-voltage and temperature history data based on three different ESS and EV operating scenarios: (a) peak shaving (PS), (b) renewable integration (RI), and (c) frequency regulation (FR), provided by the Korea Electric Power Corporation (KEPCO) research institute, and (d) the urban dynamometer driving schedule (UDDS) and (e) the worldwide harmonized light vehicles test procedure (WLTP). $(\mathrm{f}, \mathrm{g})$ Capacity retention over one year of ESS and EV operations.

\section{Supplementary Files}

This is a list of supplementary files associated with this preprint. Click to download.

- SupportingInformationFinal.docx 